\section{Reproductive allocation of two dioecious Rhamnus species in temperate forests of northeast China}

\author{
Juan Wang ${ }^{(1)}$, Chunyu Zhang ${ }^{(1)}$, Xiuhai Zhao ${ }^{(1)}$, Klaus von Gadow ${ }^{(2)}$
}

When a plant increases resource allocation to reproduction from its limited reserves, the allocation to the other functions is reduced. Because of these trade-offs, differences in reproductive allocation are believed to result in relative differences in life history traits. Dioecious plants provide an excellent opportunity for detecting such possible trade-offs in resource allocation. This study aims to present a finding about the gender-based cost of reproductive allocation. The trade-off between reproduction and foliage biomass allocation was examined in Rhamnus davurica and Rhamnus schneideri at different modular levels (shoot/sub-branch, branch, and shrub/tree level). There were no intra-annual trade-offs between reproduction and foliage biomass in either sex of either species at shoot/sub-branch level, branch level and shrub level. Interannual trade-offs were detected in females for both species. Inter-annual trade-offs existed at all three different modular levels in $R$. schneideri females, while the evidence of inter-annual trade-offs was only detected at branch level in $R$. davurica females. At the population level, the sex ratio was female-biased in 2010, and it did not significantly deviate from 1:1 in 2011 in $R$. davurica. However, the sex ratios were significantly female-biased in both 2010 and 2011 in $R$. schneideri. This study show that the degree of autonomy of the different plant organs influences the trade-offs between reproduction and growth, which suggests a species- and sex-dependent modular autonomy.

Keywords: Inter-annual Trade-off, Intra-annual Trade-off, Dioecious Species, Modular Autonomy

\section{Introduction}

Individuals that have superior lifetime reproduction are often more successful in the face of natural selection. However, when reproductive events happen, these often lead to reduced foliage growth (Karlsson \& Méndez 2005) and delayed future reproduction (Obeso 2002). The resources that plants obtain from their environment are allocated to growth, maintenance and reproduction (Willson 1983, Bazzaz et al. 1987). It may be assumed that, when a plant increases resource allocation to reproduction, the allocation to the other functions is reduced. Because of these trade-offs, differences in reproductive allocation are believed to result in relative differences in life history traits, like sea-

son-related flowering, fruiting and growth.

Dioecious plants provide an excellent opportunity for detecting possible trade-offs in resource allocation. In dioecious plants, the cost of reproduction in male individuals is different from that of females (Lloyd \& Webb 1977). Females do allocate more resources to reproduction than males, and the trade-offs between growth and reproduction would be more obvious if there was a shortage of resources (Antos \& Allen 1990, Barrett \& Pannell 1998, Delph 1999). Several studies report that females, due to higher costs of reproduction, showed reduced vegetative growth (Bañuelos \& Obeso 2004), put off flowering or reduced flowering frequency (Cipollini \& Whigham 1994) and

(1) The Key Laboratory for Forest Resources \& Ecosystem Processes of Beijing, Beijing Forestry University, 100083 Beijing (China); (2) Faculty of Forestry and Forest Ecology, Georg-August-University Göttingen, Büsgenweg 5, D-37077 Göttingen (Germany)

@ Xiuhai Zhao (bfuz@163.com)

Received: Apr 24, 2013 - Accepted: Aug 02, 2013

Citation: Wang J, Zhang C, Zhao X, von Gadow K, 2014. Reproductive allocation of two dioecious Rhamnus species in temperate forests of Northeast China. iForest 7: 25-32 [online 2013-10-14] URL: http://www.sisef.it/iforest/contents/?id=ifor1020-007

Communicated by: Roberto Tognetti had higher mortality rates if resources were insufficient (Delph 1999, Obeso 2002, Ueno et al. 2006). However, some authors found that females have growth rates equivalent to (Nicotra 1999) or even higher than males (Sakai \& Burris 1985, Rovere et al. 2003). Females may have compensatory mechanisms for their higher reproductive costs (Dawson \& Geber 1999).

There is no overwhelming evidence with regard to the trade-offs between reproduction and growth in plants (Delph \& Meagher 1995). The degree of autonomy of the different plant organs might be an important reason for this (Obeso et al. 1998). In trees, if branches are autonomous units, the costs of reproduction may show up at lower modular levels, but may be compensated at higher combined modular levels, such as the crown, by non-reproductive branches (Hasegawa \& Takeda 2001). Then we can detect the tradeoffs at the branch level but not at shrub/tree level. The degree to which the individual (modular) plant organs act in response to reproductive costs is different among species (Bañuelos \& Obeso 2004).

Trade-offs are also difficult to observe in plants because of the delayed cost of reproduction. Such delayed costs may appear in the form of lower frequency of flowering (Garcia \& Antor 1995), higher mortality rates (Bierzychudek \& Eckhart 1988, Lovett Doust \& Lovett Doust 1988) or lower growth rates of females (Popp \& Reinartz 1988). Fox \& Stevens (1991) found a tradeoff between current reproduction and subsequent reproduction in Lindera benzoin, Cipollini \& Whigham (1994) in Salix alaxensis, while Nicotra (1999) detected a delayed cost of reproduction in both males and females of Siparuna grandiflora.

According to Delph (1999), only $29 \%$ of dioecious species have a 1:1 sex ratio, while $57 \%$ are male-biased and relatively few are female-biased. The reason for the malebiased sex ratios may be that males allocate fewer resources to reproduction than females and selection often tend to favor the sex with lower reproductive investment. However, some studies report that several populations in the genus Salix have female-biased sex ratios (Elmqvist et al. 1988, Dawson \& Bliss 1989). Differences in the costs of reproduction between neighboring males and females competing for resources as well as genetic effects can also form biased sex ratios (Hamilton 1967, Taylor 1999).

This study examines the differences in reproductive costs between the sexes of two dioecious species, Rhamnus davurica and Rhamnus schneideri var. manshurica. We aim to show possible trade-offs between reproduction and vegetative growth. Accordingly, specific objectives are: (1) to evaluate the intra-annual trade-offs between repro- 


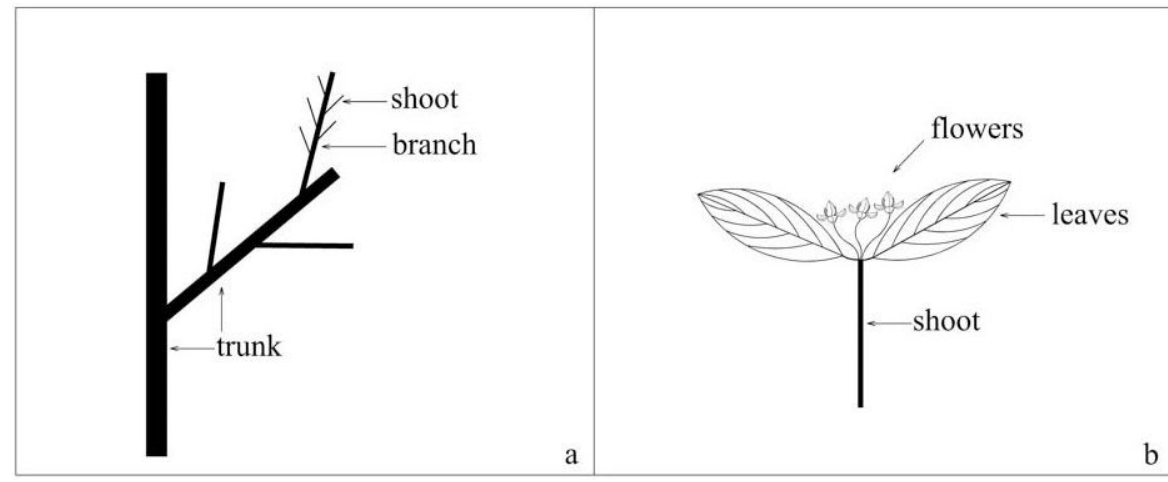

Fig. 1 - Sketch of phytomorph in dioecious Rhamnus species. (a): trunk and living branches; (b): a short current-year shoot.

duction and vegetative growth at different plant organ (modular) levels; and (2) to compare inter-annual trade-offs between females and males.

\section{Materials and methods}

\section{Study sites}

This research was conducted at the Jiaohe experimental forest in Jilin province, in northeastern China $\left(43^{\circ} 58^{\prime} \mathrm{N}, 127^{\circ} 43^{\prime} \mathrm{E}\right.$; elevation $450 \mathrm{~m}$ a.s.1.). A permanent plot was established in 2009, covering a rectangular area of 23.76 ha $(660 \times 360 \mathrm{~m})$. The forest type is a mixed broadleaf-conifer forest, in which the average annual temperature is $3.8^{\circ} \mathrm{C}$. The hottest month is July with a mean day temperature of $21.7{ }^{\circ} \mathrm{C}$, while the coldest month is January with an average day temperature of $-18.6{ }^{\circ} \mathrm{C}$. The mean annual precipitation is $695.9 \mathrm{~mm}$. The main coniferous species in the forest are Abies holophylla and Pinus koraiensis, while the dominant deciduous species are Fraxinus mandshurica, Tilia amurensis and Acer mono (Zhang et al. 2011).

The two species studied are Rhamnus davurica and Rhamnus schneideri var. manshurica. $R$. davurica occurs as a shrub or small tree, while $R$. schneideri var. manshurica only occurs as a shrub. Both species are common at the study site. $R$. davurica is usually taller than $R$. schneideri var. manshurica. Most individuals of both species have a single trunk, a few have double or multiple trunks. Both sexes are similar in vegetative phytomorph, but not in flowers. The flower is yellowish green with four petals. There are four stamens in a male flower, but only one stigma in a female flower. The phytomorphs in the Rhamnus species are shown in Fig. 1. In order to understand the classification standard, we just show male flowers in Fig. 1. Female flowers grow on the shoot in the same way as male flowers.

\section{Field measurements}

The spatial distributions of the two studied species within the $360 \times 660 \mathrm{~m}$ experimental plot are shown in Fig. S1 of the Supplementary Material. In order to examine the reproductive and vegetative allocation, female and male trees were observed in May 2010 and 2011. The numbers differ between years because not all plants were flowering and fruiting in both years. For this reason, a subset of trees was selected for analysis including only those individuals that were flowering and fruiting in both years. This involved 21 female and 18 male $R$. davurica and $57 \mathrm{fe}$ male and 19 male $R$. schneideri. Five to ten reproductive branches were randomly selected in eight crown compartments (four horizontal sections and two vertical layers, following Henriksson 2001). The number of reproductive branches was different because some individuals were very small and had no more than 5 reproductive branches.

Tab. 1 - Equations for calculating biomass and reproductive ratio $(R R) . D W_{\text {fruits, }} D W_{\text {flower, }}$, $N_{\text {flowers }}$ and $N_{\text {fruits }}$ are the dry weight of one fruit, one flower, flower number and fruit number, respectively. $B_{\text {rep }}$ is the sum of flower and fruit biomass for females or flower biomass for males; $B_{\text {veg }}$ is the leaf biomass for both sexes.

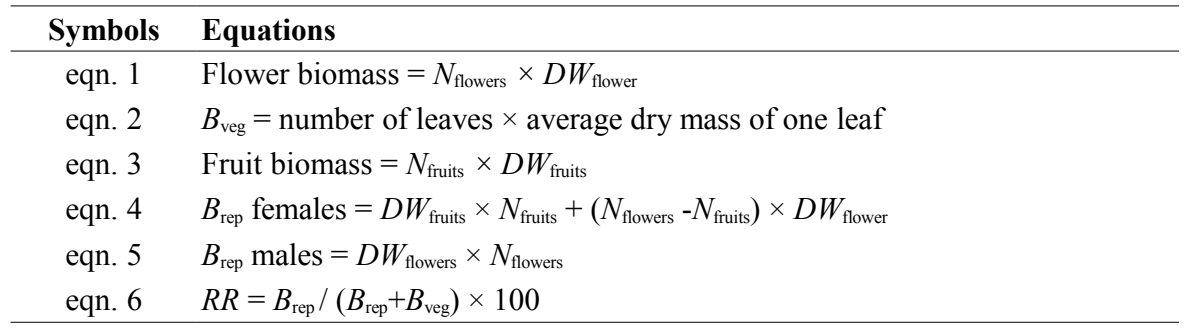

The trade-off between reproduction and growth was studied at four modular levels (shoot/sub-branch, branch, tree/shrub and population level). We counted the flowers, leaves and fruits on all selected branches in May (flowering season) and August (fruiting season). At shoot/sub-branch level, the number of flowers, leaves and fruits was assessed. At the shrub/tree level, the number of branches was counted in every sample tree. That number was multiplied by the mean number of flowers, leaves and fruits of randomly selected branches on each individual tree. This approach produced an estimate of the number of flowers, leaves and fruits on a single tree. At the time of flowering, one reproductive branch (including flowers and leaves) was harvested in each sample trees for both sexes. At the time of fruiting, 10-20 fruits were harvested on each female sample tree from the eight crown sections described above.

The harvested branches and fruits were weighed after oven-drying at $80{ }^{\circ} \mathrm{C}$ for 2 days to obtain an estimate of the average weight for each sample tree. The flower, leaf and fruit biomass estimates were calculated using eqn. 1-3 in Tab. 1 . The relative reproductive ratio $(R R)$ was calculated using eqn. 4-5 in Tab. 1. All calculations were done for different modular levels.

Growth diameter was estimated by yearring analysis. Altogether, 64 trees $(R$. davurica: 20 females and 16 males; $R$. schneideri: 11 females and 17 males) were harvested in 2010. Across-sectional stem discs were cut 5 $\mathrm{cm}$ above ground level. Tree-ring widths were measured to the nearest $0.001 \mathrm{~mm}$ using the annual ring analyzer (Lintab 5). The tree ring samples were cross-dated using COFFCHA software.

\section{Statistical analysis}

Sometimes, it is difficult to decide if an effect is fixed or random (Crawley 2007). Therefore, differences in flower biomass, leaf mass and reproductive ratio at three levels were compared by factorial analyses of variance with two fixed-effects factors (sex and year). Pearson correlations were used to test the correlation between foliage biomass and reproductive biomass. Trees were grouped into diameter at breast height (DBH) classes. The sex ratio in each DBH class was determined during the study period. G-tests were used to analyze deviations from a 1:1 sex ratio for the two species in different years.

\section{Results}

Shoot/sub-branch level analysis

Both dioecious species, $R$. davurica and $R$. schneideri, show significant differences between females and males at the shoot level (Tab. 2). The differences between sexes in 
Tab. 2 - Results of analyses of variance examining the effects of sex and year on the flower, foliage, and the percentage of reproductive ratio $(R R)$ at different modular level in Rhamnus species . $\left.{ }^{* * *}\right)$ : $\mathrm{p}<0.001 ;\left({ }^{* *}\right): \mathrm{p}<0.01 ;\left({ }^{*}\right)$ : $\mathrm{p}<0.05$.

\begin{tabular}{|c|c|c|c|c|c|c|c|c|}
\hline \multirow{2}{*}{$\begin{array}{l}\text { Modular } \\
\text { level }\end{array}$} & \multirow{2}{*}{ Species } & \multirow{2}{*}{$\begin{array}{l}\text { Source of } \\
\text { variation }\end{array}$} & \multicolumn{2}{|c|}{ Flower } & \multicolumn{2}{|c|}{ Foliage biomass } & \multicolumn{2}{|c|}{$\mathbf{R R}$} \\
\hline & & & Mean Sq & F value & Mean Sq & F value & Mean Sq & F Value \\
\hline \multirow[t]{8}{*}{ Shoot } & R. davurica & sex & 0 & $5.94^{*}$ & 3.6 & $18.63^{* * *}$ & 0.04 & $25.80^{* * *}$ \\
\hline & & year & 0 & $25.01^{* * *}$ & 12.86 & $66.61^{* * *}$ & 0.03 & $21.67^{* * * *}$ \\
\hline & & sex $\times$ year & 0 & 0.04 & 0.23 & 1.2 & 0.03 & $23.22^{* * * *}$ \\
\hline & & Residuals & 0 & - & 0.19 & - & 0 & - \\
\hline & R. schneideri & sex & 0 & $46.60^{* * *}$ & 0.01 & 2.8 & 0.45 & $124.10^{* * * *}$ \\
\hline & & year & 0 & $188.04^{* * *}$ & 0.12 & $27.38^{* * *}$ & 0.65 & $179.04^{* * *}$ \\
\hline & & sex $\times$ year & 0 & $142.49^{* * *}$ & 0.01 & 3.01 & 0.44 & $121.45^{* * *}$ \\
\hline & & Residuals & 0 & - & 0 & - & 0 & \\
\hline \multirow[t]{8}{*}{ Branch } & R. davurica & sex & 0 & 0.11 & 34.49 & $8.86^{* *}$ & 0.12 & $56.80^{* * * *}$ \\
\hline & & year & 0 & 0.26 & 210.06 & $53.96^{* * *}$ & 0.15 & $69.97^{* * *}$ \\
\hline & & sex $\times$ year & 0.01 & $8.80^{* *}$ & 0.16 & 0.04 & 0.14 & $63.24^{* * *}$ \\
\hline & & Residuals & 0 & - & 3.89 & - & 0 & - \\
\hline & R. schneideri & sex & 0 & 0 & 87.66 & $63.00^{* * * *}$ & 0.46 & $58.10^{* * * *}$ \\
\hline & & year & 0.32 & $65.95^{* * *}$ & 233.89 & $168.09^{* * *}$ & 0.83 & $103.73^{* * *}$ \\
\hline & & sex $\times$ year & 0.22 & $46.59^{* * *}$ & 78.51 & $56.43^{* * *}$ & 0.55 & $68.61^{* * *}$ \\
\hline & & Residuals & 0 & - & 1.39 & - & 0.01 & - \\
\hline \multirow[t]{8}{*}{ Shrub } & R. davurica & sex & 30.6 & 4.22 & 122452.19 & 2.35 & 0.04 & $16.83^{* *}$ \\
\hline & & year & 12.11 & 1.67 & 150.66 & 0 & 0.02 & $9.34^{* *}$ \\
\hline & & sex×year & 9.54 & 1.31 & 33945.72 & 0.65 & 0.02 & $9.01^{* *}$ \\
\hline & & Residuals & 7.26 & - & 52066.45 & - & 0 & \\
\hline & R. schneideri & sex & 9.18 & 0.32 & 53268.3 & 1.81 & 0.17 & $10.59^{* *}$ \\
\hline & & year & 373.96 & $12.97^{* * *}$ & 137588.25 & $4.67^{*}$ & 0.24 & $15.60^{* * *}$ \\
\hline & & sex×year & 39.02 & 1.35 & 110844.39 & 3.76 & 0.13 & $8.29^{* *}$ \\
\hline & & Residuals & 28.83 & - & 29456.93 & - & 0.02 & - \\
\hline
\end{tabular}

Fig. 2 - Comparison of reproductive ratio and foliage biomass between males and females in 2010 and 2011 at shoot/sub-branch levels for the two Rhamnus species studied. Letters denote significant differences $(\mathrm{p}<0.05)$, calculated using multiple comparisons. Error bars represent standard errors.
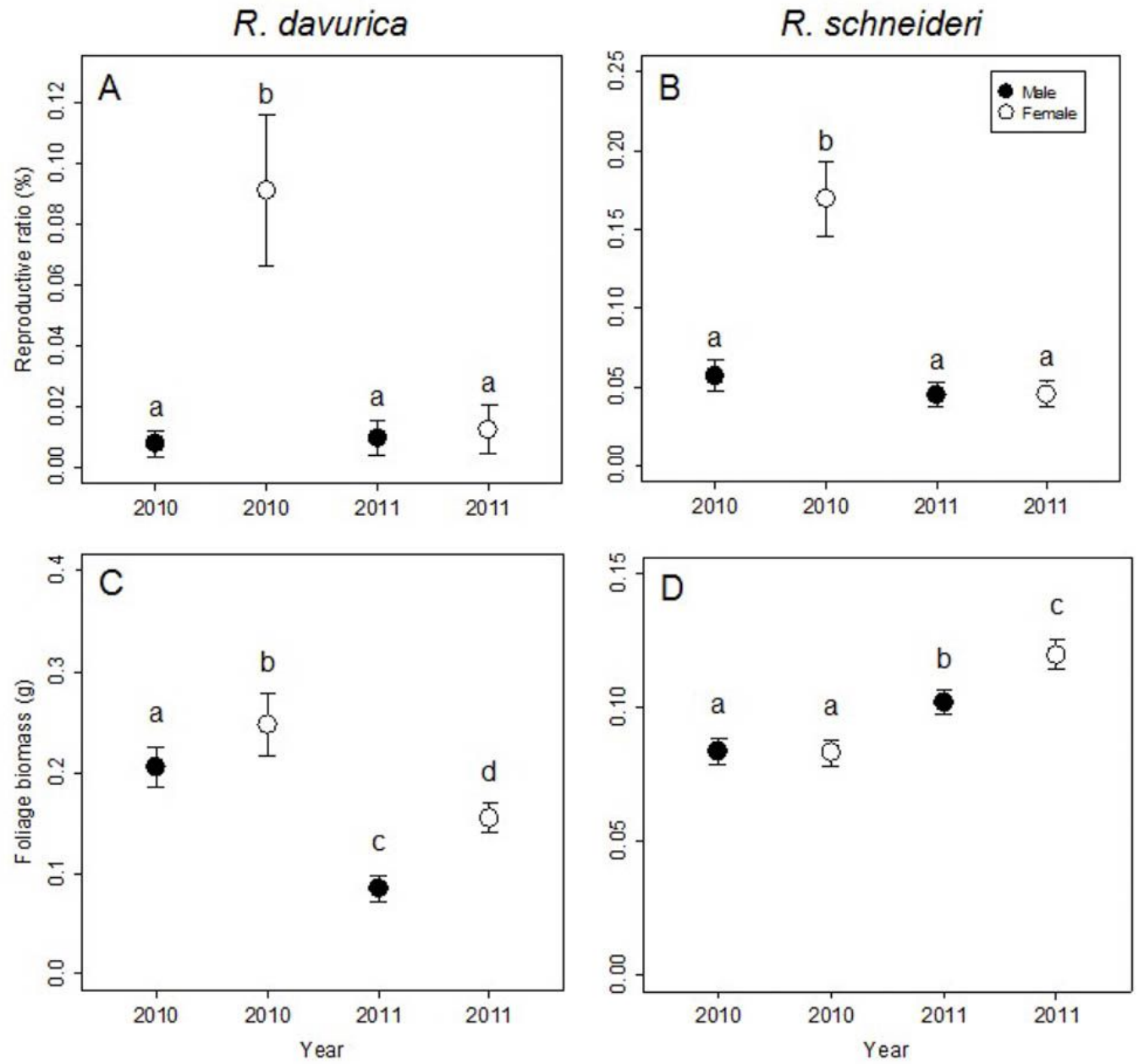
Tab. 3 - Results of a correlation analysis between reproductive biomass and foliage biomass at the shoot/sub-branch and branch level based on the study data in 2011. Only the branches with eight or more shoots could be used in the analysis. Finally, 8 of 196 branches of female $R$. davurica, 26 of 178 branches of male $R$. davurica, 344 of 461 branches of female $R$. schneideri and 177 of 183 branches of male R. schneideri were used. Only the shrubs with 8 or more branches could be used in the correlation analysis. Finally, 12 of $21 R$. davurica females, 18 of $18 R$. davurica males, 57 of $57 R$. schneideri females and 19 of $19 R$. schneideri males were used.

\begin{tabular}{lllcccc}
\hline Unit & Species & Sex & $\begin{array}{c}\text { Significant } \\
\text { negative }\end{array}$ & $\begin{array}{c}\text { Significant } \\
\text { positive }\end{array}$ & $\begin{array}{c}\text { Non- } \\
\text { significant }\end{array}$ & Total \\
\hline Branch & $R$. davurica & Female & 0 & 0 & 8 & 8 \\
& & Male & 0 & 0 & 26 & 26 \\
\cline { 2 - 6 } & R. schneideri & Female & 3 & 28 & 313 & 344 \\
& & Male & 5 & 51 & 121 & 177 \\
\hline Shrub & R. davurica & Female & 0 & 4 & 8 & 12 \\
& & Male & 0 & 8 & 10 & 18 \\
\cline { 3 - 7 } & R. schneideri & Female & 1 & 9 & 47 & 57 \\
& & Male & 0 & 13 & 6 & 19 \\
\hline
\end{tabular}

flower biomass and reproductive ratio were significant for both species, though differences between sexes in foliage biomass were significant only for $R$. davurica (Tab. 2). $R$. schneideri females invested more flower biomass than males in 2010, while $R$. schneideri males invested more flower biomass than females in 2011 (Fig. S2 in Sup productive ratios than males in 2010 in both species (Fig. 2a, b). R. davurica females invested more foliage biomass than males in both years, while in $R$. schneideri only females produced more foliage biomass than males in 2011 (Fig. 2c, d).

No significant correlations were found plementary Material). Females had higher re- between reproductive biomass and foliage biomass at the shoot/sub-branch level in $R$. davurica (Tab. 3). In $R$. schneideri, only a few branches (female: 3 of 344 branches; male: 5 of 177 branches) showed significant negative correlations, while most branches exhibited significant positive correlations between reproductive biomass and foliage biomass (Tab. 3). This means that when a shoot shows higher growth rate, it also invests more in reproduction. The significant negative correlation can be considered as a trade-off between reproduction and vegetation. Therefore, there is no evidence of a trade-off at shoot level. The observation may be attributed to more resources being available at a higher level.

The differences between years in flower biomass, foliage biomass and reproductive ratio were significant for both species (Tab. 2 ). The reproductive ratio decreased for the females in both species. For the males in both species the differences in the reproductive ratio between years was not significant (Fig. 2a, b). A long-term cost of reproduction was detected at the shoot/sub-branch level just for females. The reproductive ratio decreased for females in both species (Fig. $2 \mathrm{a}, \mathrm{b})$. The foliage biomass decreased for both sexes in $R$. davurica, while foliage bio-
R. davurica
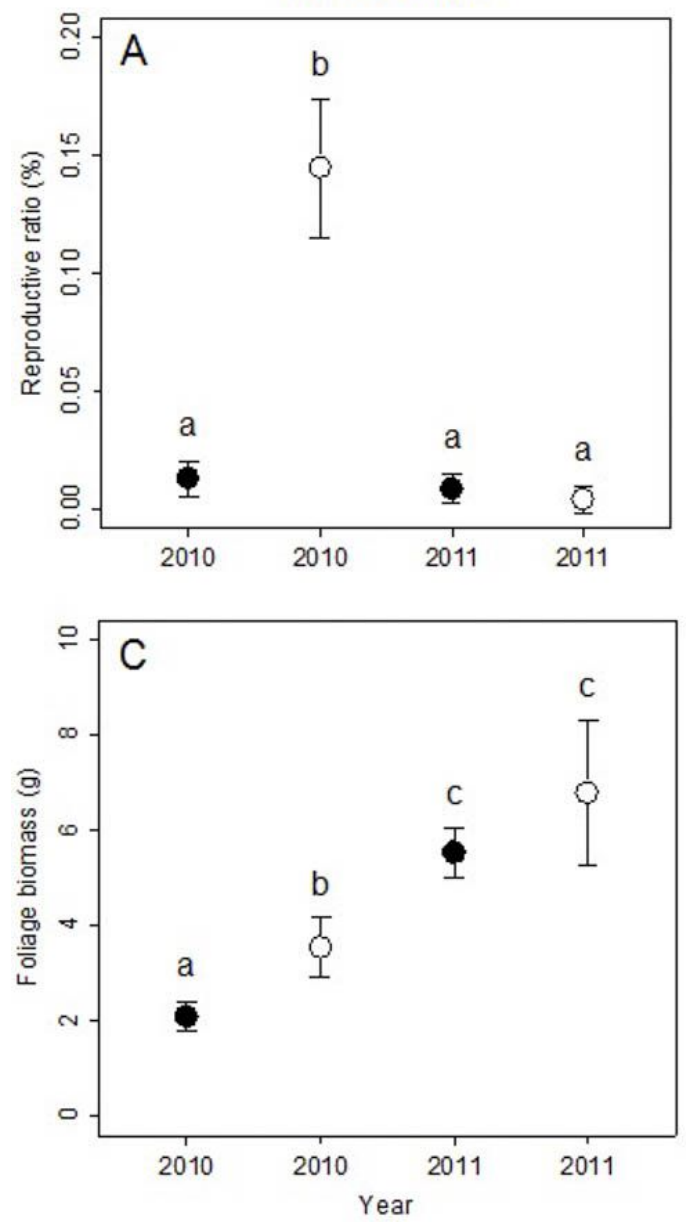

R. schneideri
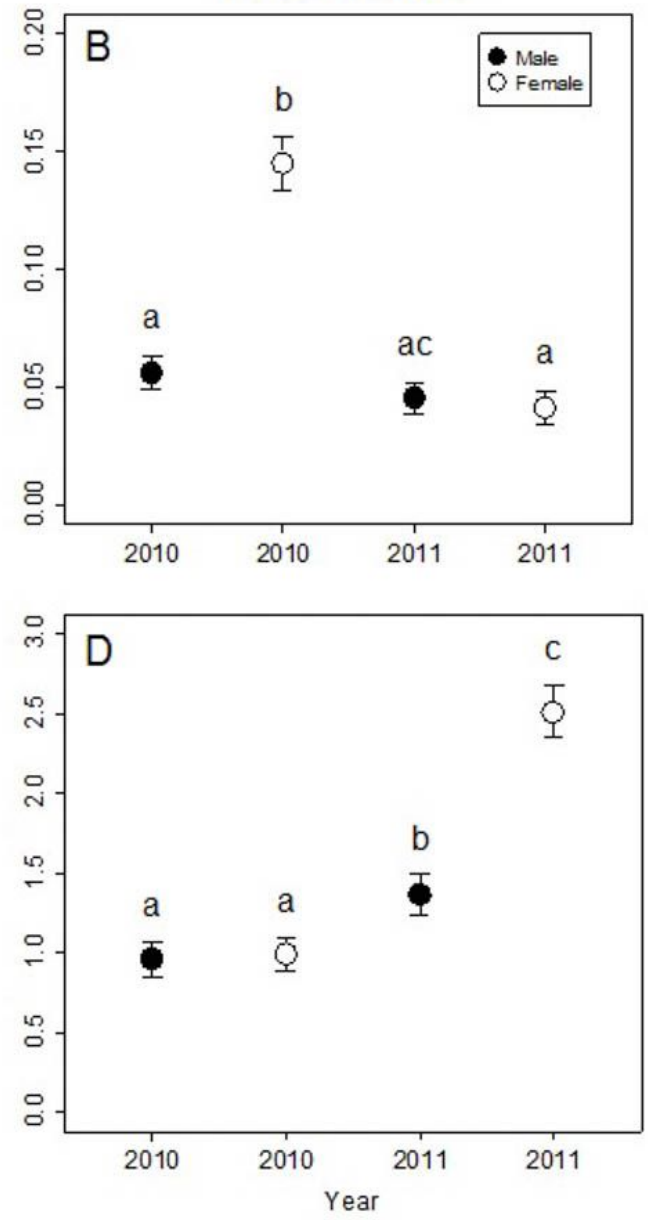

Fig. 3 - Comparison of reproductive ratio and foliage biomass between males and females in 2010 and 2011 at the branch level for the two Rhamnus species studied. Letters denote significant differences $(\mathrm{p}<0.05)$, and are calculated using multiple comparisons. Error bars represent standard errors. 
Fig. 4 - Comparison of reproductive ratio and foliage biomass between males and females in 2010 and 2011 at the shrub/tree level for the two Rhamnus species studied. Letters denote significant differences $(\mathrm{p}<0.05)$, calculated using multiple comparisons. Error bars represent standard errors.
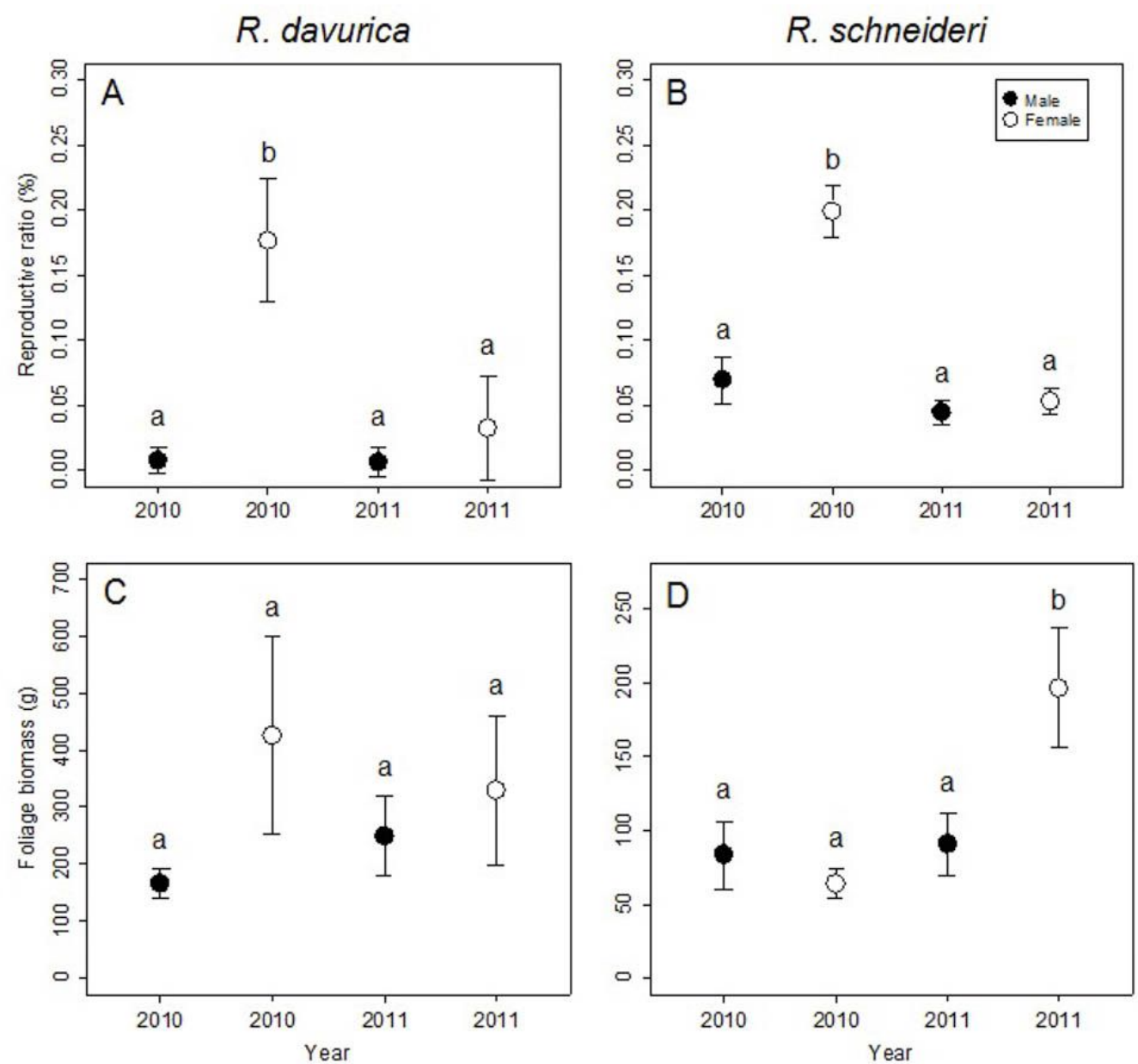

mass increased for both sexes in $R$. schneideri (Fig. 2c, d). Flower biomass and fruit biomass decreased for females of both species. Flower biomass decreased for $R$. davurica males, but there was not significant difference between years in the flower biomass for $R$. schneideri males (Fig. S3 in Supplementary Material).

\section{Branch level analysis}

At the branch level, no significant differences were detected between sexes in flower biomass for both $R$. davurica and $R$. schneideri. However, differences between sexes in both foliage biomass and reproductive ratio were significant for both species (Tab. 2). $R$. davurica (in 2010) and $R$. schneideri (in 2011) showed significant differences between sexes in foliage biomass. The difference in reproductive ratio between males and females was significant in both $R$. davurica and R. schneideri in 2010 (Fig. 3a, b).

At the branch level, almost all 106 shrubs/ small trees ( $R$. davurica: 12 females and 18 males; $R$. schneideri: 57 females and 19 males) showed significant positive or nonsignificant correlation between reproductive biomass and foliage biomass apart from one female $R$. schneideri (Tab. 3). This means no trade-off exists between reproduction and
Tab. 4 - Number of stems and sex ratios of two Rhamnus species in different DBH classes in the $360 \times 660 \mathrm{~m}$ research plot. $(\mathrm{DBH})$ : diameter at breast height $(\mathrm{cm}) ; \mathrm{G}(\mathrm{P})$ : G-test results. (None): non-flowering trees; $(* * *): p<0.001 ;(* *): p<0.01 ;(*): p<0.05$ : (ns): $p>0.05$.

\begin{tabular}{llccccc}
\hline \multirow{2}{*}{ Species } & Parameters & \multicolumn{6}{c}{ DBH classes (cm) } \\
\cline { 2 - 7 } in davurica 2010 & Male & $\mathbf{0 - 2}$ & $\mathbf{2 - 4}$ & $\mathbf{4 - 6}$ & $\mathbf{6 - 8}$ & $>\mathbf{8}$ \\
& Female & 9 & 22 & 18 & 11 & 0 \\
& None & 11 & 88 & 136 & 62 & 19 \\
& Male/Female & 0.33 & 0.28 & 0.13 & 0.18 & 0 \\
& G(P) & $3.01^{\text {ns }}$ & $33.08^{* * *}$ & $102.07^{* * *}$ & $39.04^{* * *}$ & $25.66^{\text {*** }}$ \\
\hline R. davurica & Male & 1 & 16 & 14 & 6 & 0 \\
in 2011 & Female & 3 & 18 & 21 & 11 & 0 \\
& Non-flowering & 13 & 131 & 182 & 78 & 28 \\
& Male/Female & 0.33 & 0.89 & 0.67 & 0.55 & - \\
& G(P) & $0.93^{\text {ns }}$ & $0.12^{\text {ns }}$ & $1.39^{\text {ns }}$ & $1.45^{\text {ns }}$ & - \\
\hline R. schneideri & Male & 1 & 21 & 1 & - & - \\
in 2010 & Female & 11 & 73 & 4 & - & - \\
& Non-flowering & 1 & 10 & 1 & - & - \\
& Male/Female & 0.09 & 0.29 & 0.25 & - & - \\
& G(P) & $9.36^{*}$ & $30.29^{* * *}$ & $1.75^{\text {ns }}$ & - & - \\
\hline R. schneideri & Male & 5 & 29 & 0 & - & - \\
in 2011 & Female & 8 & 57 & 3 & - & - \\
& Non-flowering & 4 & 22 & 1 & - & - \\
& Male/Female & 0.63 & 0.51 & 0 & - & - \\
& G(P) & $0.67^{\text {ns }}$ & $9.23^{*}$ & $3.56^{\text {ns }}$ & - & - \\
\hline
\end{tabular}




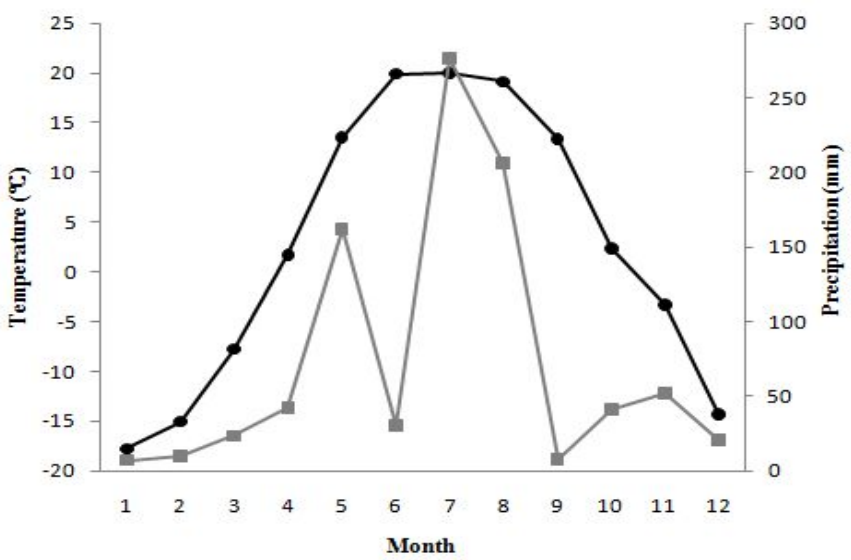

2011

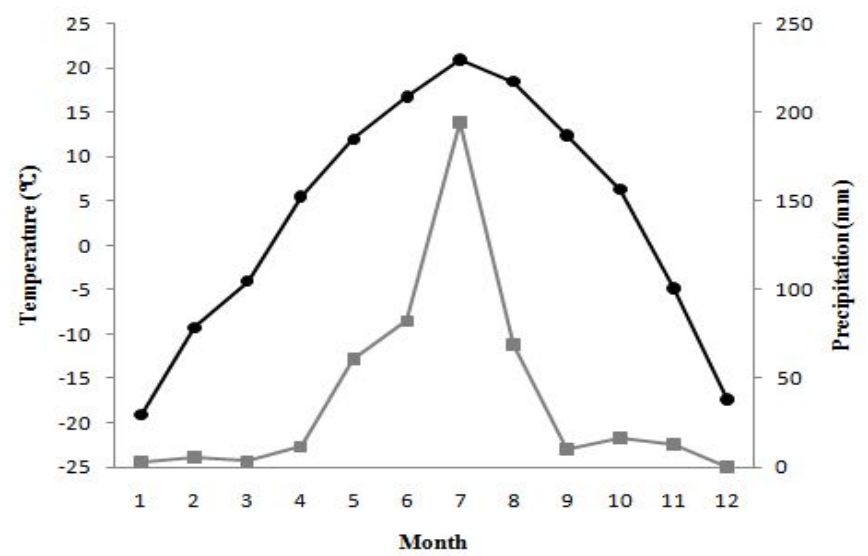

Fig. 5 - Monthly average temperature and monthly average precipitation in 2010 and 2011. The black dots indicate temperature, the grey squares indicate precipitation.

vegetation at branch level for two dioecious Rhamnus species.

The differences between years in foliage biomass and reproductive ratio were significant for both species, while the difference between years in flower biomass were significant in $R$. schneideri (Tab. 2). The reproductive ratio of females decreased in the subsequent year, while that of males was not significantly different for both species. This result is assumed to provide evidence of a delayed cost of reproduction for females at the branch level. The foliage biomass of males and females increased in the subsequent year for both dioecious species (Fig. $3 \mathrm{c}, \mathrm{d})$. The decrease of reproductive ratio and the increase of foliage biomass in females indicated inter-annual tradeoffs at branch level.

\section{Shrub/tree level analysis}

At the shrub/tree level, significant differences in reproductive ratio were detected between males and females for both $R$. davurica and $R$. schneideri, though no significant differences in flower biomass and foliage biomass were found (Tab. 2). Females invested more biomass into reproduction than males for both species in 2010, but there was no significant difference between sexes in reproductive allocation for both species in 2011 (Fig. 4a, b). The reproductive biomass correlated positively with the foliage biomass in the females of the two species at the shrub/tree level $(R$. davurica, Male: $\mathrm{t}=1.12$, correlation coefficient $=0.24, p>0.05 ; \mathrm{Fe}$ male: $\mathrm{t}=3.33$, correlation coefficient $=0.74$, $\mathrm{p}<0.01 ;$ R. schneideri, Male: $\mathrm{t}=0.76$, correlation coefficient $=0.15, \mathrm{p}>0.05$; Female: $\mathrm{t}=$ 2.73 , correlation coefficient $=0.33 ; \mathrm{p}<0.01$ ) Thus, there was no trade-off between vegetative growth and reproduction in males and females of the two species.

Differences between years in flower bio- mass, foliage biomass and reproductive ratio were significant for $R$. schneideri, but the difference between years was significant only in the reproductive ratio for $R$. davurica (Tab. 2). Both dioecious species showed different reproductive ratios in 2010 and 2011. The reproductive ratios of females decreased in the subsequent year for both species, while no significant difference was detected between the two years in males. Interestingly, the leaf biomass in female $R$. schneideri also increased in the subsequent year (Fig. 4c, d). These differences in the reproductive ratios between the two years may be due to a delayed costs of reproduction.

\section{Population level}

The sex ratio of $R$. davurica in 2010 was significantly female-biased, but it was $1: 1$ in 2011. The sex ratios in each $D B H$ class were consistent with the population sex ratio apart from the 1-2 $\mathrm{cm} D B H$ class (Tab. 4, Fig. S4 in Supplementary Material). The sex ratios of $R$. schneideri were significantly biased in both 2010 and 2011 , apart from the $0-2 \mathrm{~cm}$ and 4-6 cm classes (Tab. 4, Fig. S4 in Supplementary Material).

The age of females and males was not significantly different $(R$. davurica: $36.92 \pm$ 1.4 years for males, $38.5 \pm 1.63$ years for females, $t=0.74, p=0.47 ; R$. schneideri: $53.73 \pm 1.46$ years for males, $49.39 \pm 2.02$ years for females, $t=-1.74, p=0.09$ ). The radial growth of $R$. schneideri showed inter-sexual differences with the growth rate of females being higher than that of males $(R$. davurica: $0.79 \pm 0.03 \mathrm{~mm} \cdot$ year $^{-1}$ for males, $0.84 \pm 0.03 \mathrm{~mm} \cdot$ year $^{-1}$ for females, $t=0.97$, $p=0.34 ; R$. schneideri: $0.31 \pm 0.02 \mathrm{~mm}$. year $^{-1}$ for males, $0.37 \pm 0.02 \mathrm{~mm} \cdot$ year $^{-1}$ for females, $t=2.67, p=0.008643$ - Fig. S4). The variation of monthly average temperature and precipitation was similar in 2010 and 2011 (Fig. 5).

\section{Discussion}

\section{Intra-annual trade-off at different} modular levels

Annual trade-off means that the correlation between foliage biomass and reproductive ratio is negative at 1 year. Namely, for each high reproductive biomass, there is a low foliage biomass. Unexpectedly, most males and females showed a non-significant correlation between foliage biomass and reproductive biomass for both species studied. Only a few individuals showed a trade-off at both the shoot/sub-branch level and branch level in $R$. schneideri. This findings indicate that, although some shoots and branches showed autonomy, the degree of modular autonomy was different between species, sexes and shrubs of the same sex.

The reproductive biomass was positively correlated with the foliage biomass at different levels for both sexes in $R$. schneideri. In $R$. davurica, the reproductive biomass was positively correlated with the foliage biomass among branches/shrubs, but neutral among shoots for both sexes. The positive correlation is probably due to the particular position of the shoots and/or branches. The better the position (e.g., full light exposure), the more foliage growth and reproduction that can be expected (Bañuelos \& Obeso 2004). Plant compensatory mechanisms may probably hide the trade-offs (Munetaka et al. 2009). During the investigation, we found that the flowers and immature fruits of both species were all green. These organs may also represent photosynthetic structures that can compensate the reproductive cost of a plant (Tozawa et al. 2009). Thus, females may have a greater compensatory advantage than males because of flower and fruit photosynthesis. Phenology patterns may provide another compensatory mechanism for reproduction. Both $R$. davurica and $R$. schneideri 
grow leaves before flowers. If a leaf is growing before flowering, a plant will first allocate more resources to foliage growth than to reproduction. Trade-off can be detected only for a short time when flowers and leaves are both on a tree. Thus, the trade-off cannot be determined during the entire reproductive period, (Miyazaki et al. 2002). Interestingly, Verdú et al. (2007) found that the lower cost of reproduction for Fraxinus ornus males results in better vegetative growth than in the hermaphrodites of that species. Such differences in sex-specific reproductive costs do not seem to be anymore significant under stressful conditions.

\section{Inter-annual trade-off at different modular levels}

Delayed costs of reproduction were found at different modular levels for the two dioecious species. The delayed cost was detected in $R$. schneideri females and $R$. davurica females at shoot, branch and shrub levels, but not in males. The fruit biomass decreased at most modular levels in the subsequent year in $R$. davurica females. However, the fruit biomass decreased at shoot level but not a any other higher modular levels in the subsequent year in $R$. schneideri females. This indicates that different species may have different reproductive strategies. Every single shoot of $R$. schneideri female decreased in the fruit biomass, but the number of fruits a higher modular levels may increase in the subsequent year.

At three different modular levels, the reproductive ratio decreased, while the foliage biomass increased in $R$. schneideri females. This result suggests the existence of an interannual trade-off in $R$. schneideri females, being the performances consistent at three different modular levels. In $R$. davurica, the inter-annual trade-offs only existed at branch level for females. Some studies found that the reproduction pattern of the lower-level modules was the same as the higher-level modules (e.g., Matsushita et al. 2011). Our study also confirmed the same performance in R. schneideri. Newell (1991) found that branches allocated more resources for reproduction and had less opportunity to flower or bear fruit in the subsequent year than on previously non-fruiting branches. Thus, reproductive activity in a given year may cause reduced fruit biomass in the subsequent year. Vaughton \& Ramsey (2011) also found that Leucopogon melaleucoides females, which invest more energy in reproduction, will inhibit future growth in resource-limiting conditions and have no compensatory traits. No significant difference in monthly average temperature and precipitation was found between 2010 and 2011. In this study, climatic parameters may not be the key factors for the inter-annual trade-off.

Sex ratio is an important trait at the popula- tion level for dioecious species. The sex ratio is affected at germination by sex-linked genes (Shelton 2010), pollination intensity (Field et al. 2012) and soil nitrogen (Yu \& $\mathrm{Lu}$ 2011). Sex ratios are affected by other factors as well, e.g., sexually different mortality rates (Stehlik \& Barrett 2005). The sex ratio changed at reproduction from a significant female-bias in 2010 to a non-significant bias in 2011, because more females did not flower in 2011 in $R$. davurica. The change in sex ratio within two reproductive years may be an indication of a delayed cost at the population level. The lower flowering frequency in females may be the evidence of a long-term cost of reproduction (Cipollini \& Stiles 1991).

\section{Conclusions}

The intra-annual trade-off between foliage biomass and reproductive structure was not detected at different modular levels neither in sex nor in Rhamnus species. The performances of inter-annual trade-offs were different at two sexes and two Rhamnus species. The inter-annual trade-offs were just detected in females for both Rhamnus species, although the performances were different between two species at four modular levels. The intra-annual trade-off is hardly clear because of compensatory mechanism in both sexes, while the inter-annual trade-off is clear in females because of their higher reproductive allocation.

\section{Acknowledgments}

This research is supported by the Special Research Program for Forestry Welfare of China (200904022) and the $12^{\text {th }}$ five-year National Science and Technology Plan of China (2012BAC01B03), the National Natural Science Foundation of China (31200315), the Program for New Century Excellent Talents in University of Ministry of Education of China (NCET-12-0781) and the Program of the Co-Construction with Beijing Municipal Government of China (2012).

\section{References}

Antos JA, Allen GA (1990). A comparison of reproductive effort in the dioecious shrub Oemleria cerasiformis using nitrogen, energy and biomass, as currencies. American Midland Naturalist 124: 254-262. - doi: 10.2307/2426174

Barrett SCH, Pannell JR (1998). Baker's law revisited: reproductive assurance in a metapopulation. Evolution 52: 657-668. [online] URL: http://www.jstor.org/stable/2411261

Bazzaz FA, Chiariello NR, Coley PD, Pitelka LF (1987). Allocating resources to reproduction and defense. BioScience 37: 58-67. - doi: 10.2307/ 1310178

Bañuelos MJ, Obeso JR (2004). Resource allocation in the dioecious shrub Rhamnus alpinus: the hidden costs of reproduction. Evolutionary Eco- logy Research 6: 397-413. [online] URL: http:// www.unioviedo.es/mjbanuelos/pdfs/BaOb_04_E volEcolRes.pdf

Bierzychudek P, Eckhart V (1988). Spatial segregation of the sexes of dioecious plants. American Naturalist 132: 34-43. - doi: 10.1086/284836

Cipollini ML, Stiles EW (1991). Costs of reproduction in Nyssa sylvatica: sexual dimorphism in reproductive frequency and nutrient flux. Oecologia 86:585-593. - doi: 10.1007/BF00318326 Cipollini ML, Whigham DF (1994). Sexual dimorphisms and cost of reproduction in the dioecious shrub Lindera benzoin (Lauraceae). American Journal of Botany 81:65-75. - doi: $10.2307 / 2445564$

Crawley MJ (2007). The R Book. The R Book. John Wiley and Sons Ltd., Chichester, UK, pp. 877.

Dawson TE, Bliss LC (1989). Patterns of water use and the tissue water relations in the dioecious shrub, Salix arctica: the physiological basis for habitat partitioning between the sexes. Oecologia 79: 332-343. - doi: 10.1007/BF0038 4312

Dawson TE, Geber MA (1999). Sexual dimorphism in physiology and morphology. In: "Gender and sexual dimorphism in flowering plants" (Geber MA ed). Springer, Berlin, Germany, pp. 175-215.

Delph LF, Meagher TR (1995). Sexual dimorphism masks life history trade-off in the dioecious plant Silene latifolia. Ecology 76: $775-$ 785. - doi: 10.2307/1939343

Delph LF (1999). Sexual dimorphism in live history. In: "Gender and sexual dimorphism in flowering plants" (Geber MA ed) . Springer, Berlin, Germany, pp. 149-173.

Elmqvist T, Agren J, Tunlid A (1988). Sexual dimorphism and between-year variation in flowering, fruit set and pollinator behavior in a boreal willow. Oikos 53:58-66. - doi: 10.2307/3565663 Field DL, Pickup M, Barrett SCH (2012). The influence of pollination intensity on fertilization success, progeny sex ratio, and fitness in a windpollinated, dioecious plant. International Journal of Plant Science 173: 184-191. - doi: 10.1086/ 663164

Fox JF, Stevens GC (1991). Costs of reproduction in a willow: experimental responses vs. natural variation. Ecology 72: 1013-1023. - doi: 10.2307 /1940601

Garcia MB, Antor RJ (1995). Sex ratio and sexual dimorphism in the dioecious Borderea pyrenaica (Dioscoreaceae). Oecologia 101: 59-67. doi: 10.1007/BF00328901

Hamilton WD (1967). Extraordinary sex ratios. Science 156: 477-488. - doi: 10.1126/science. 156.3774.477

Hasegawa S, Takeda H (2001). Functional specialization of current shoots as a reproductive strategy in Japanese alder (Alnus hirsute var. sibirica). Canadian Journal of Botany 79:38-48. doi: 10.1139/b00-143

Henriksson J (2001). Differential shading of branches or whole trees: survival, growth, and reproduction. Oecologia 126: 482-486. - doi: 


\subsection{7/s004420000547}

Karlsson PS, Méndez M (2005). The resource economy of plant reproduction. In: "Reproductive allocation in plants" (Reekie EG ed). Elsevier Academic Press, Burlington, MS, USA, pp. 149.

Lloyd DG, Webb CJ (1977). Secondary sex characters in plants. Botanical Review 43: 177-216. - doi: 10.1007/BF02860717

Lovett Doust J, Lovett Doust L (1988). Modules of production and reproduction in a dioecious clonal shrub, Rhus typhina. Ecology 69: 741750. - doi: 10.2307/1941023

Matsushita M, Nakagawa M, Tomaru N (2011) Sexual differences in year-to-year flowering trends in the dioecious multi-stemmed shrub Lindera triloba: effects of light and clonal integration. Journal of Ecology 99: 1520-1530. - doi 10.1111/j.1365-2745.2011.01866.x

Miyazaki Y, Hiura T, Kato E, Funada R (2002). Allocation of resources to reproduction in Styrax obassia in a masting year. Annals of Botany 89: 767-772. - doi: 10.1093/aob/mcf107

Munetaka T, Naoto U, Kenji S (2009). Compensatory mechanisms for reproductive costs in the dioecious tree Salix integra. Botany 87:315-323. - doi: 10.1139/B08-125

Newell EA (1991). Direct and delayed costs of reproduction in Aesculus californica. Journal of Ecology 79: 365-378. - doi: 10.2307/2260719

Nicotra AB (1999). Reproductive allocation and the long-term costs of reproduction in Siparuna grandiflora, a dioecious neotropical shrub. Journal of Ecology 87: 138-149 - doi: 10.1046/j.13 65-2745.1999.00337.x

Obeso JR (2002). The costs of reproduction in plants. New Phytologist 155: 321-348. - doi: 10.1046/j.1469-8137.2002.00477.x

Obeso JR, Álvarez-Santullano M, Retuerto R (1998). Sex-ratios, size distributions, and sexual dimorphism in the dioecious tree Ilex aquifolium (Aquifoliaceae). American Journal of Botany 85: 1602-1608. - doi: 10.2307/2446488

Popp JW, Reinartz JA (1988). Sexual dimorphism in biomass allocation and clonal growth of Xanthoxylum americanum. American Journal of Botany 75: 1732-1741. - doi: 10.2307/2444688

Rovere AE, Aizen MA, Kitzberger T (2003). Growth and climatic response of male and female trees of Austrocedrus chilensis, a dioecious conifer from the temperate forests of southern South America. Ecoscience 10: 195-203.

Sakai AK, Burris TA (1985). Growth in male and female Aspen clones: a twenty-five-year longitudinal study. Ecology 66: 1921-1927. - doi: $10.2307 / 2937388$

Shelton AO (2010). The origin of female-biased sex ratios in intertidal seagrasses (Phyllospadix spp.). Ecology 91: 1380-1390. - doi: 10.1890/090685.1

Stehlik I, Barrett SCH (2005). Mechanisms governing sex-ratio variation in dioecious Rumex nivalis. Evolution 59: 814-825. - doi: 10.1554/ 04-417

Taylor DR (1999). Genetics of sex ratio variation among natural populations of a dioecious plant. Evolution 53: 55-62. - doi: 10.2307/2640919

Tozawa M, Ueno N, Seiwa K (2009). Compensatory mechanisms for reproductive costs in the dioecious tree Salix integra. Botany 87: 315323. - doi: 10.1139/B08-125

Ueno N, Kanno H, Seiwa K (2006). Sexual differences in shoot and leaf dynamics in a dioecious tree, Salix sachalinensis. Canadian Journal of Botany 84: 1852-1859. - doi: 10.1139/b06-142

Vaughton G, Ramsey M (2011). Reproductive allocation and costs in gynodioecious Leucopogon melaleucoides (Ericaceae): implications for the evolution of gender dimorphism. Plant Biology 13: 888-895. - doi: 10.1111/j.1438-8677.2011. 00457.x

Verdú M, Spanos K, Kanová I, Slobodník B, Paule L (2007). Similar gender dimorphism in the costs of reproduction across the geographic range of Fraxinus ornus. Annals of Botany 99: 183-191. - doi: 10.1093/aob/mcl241

Willson MF (1983). Plant Reproductive Ecology. Wiley, New York, USA, pp. 291.

$\mathrm{Yu} \mathrm{L}$, Lu J (2011). Does landscape fragmentation influence sex ratio of dioecious plants? A case study of Pistacia chinensis in the Thousand-Island Lake region of China. PLoS One 6: e22903. - doi: 10.1371/journal.pone.0022903

Zhang CY, Wang J, Zhao XH, Xia FC, Gadow KV (2011). Sexual dimorphism in reproductive and vegetative allometry for two dioecious Rhamnus plants in north-eastern China. European Journal of Forest Research 131: 1287-1296. - doi: 10.1007/s10342-012-0598-5

\section{Supplementary Material}

Fig. S1 - Spatial distribution of Rhamnus davurica and Rhamnus schneideri var. manshurica in the $360 \times 660 \mathrm{~m}$ research plot.

Fig. S2 - Comparison of flower biomass and fruit biomass between males and females in Rhamnus shrub species at shoot level.

Fig. S3 - The annual DBH distribution in males, females and non-reproductive individuals in 2010 and 2011.

Fig. S4 - Accumulated annual ring width of males (hollow circles) and females (solid circles) for two species.

Link: Wang_1020@supp1001.pdf 